\title{
A PRODUÇÃO DE GÊNEROS DISCURSIVOS NO CIBERESPAÇO: DESAFIOS PARA OS NOVOS LETRAMENTOS
}

\author{
THE PRODUCTION OF DISCURSIVE GENRES IN CYBERSPACE: CHALLENGES FOR \\ NEW LITERACIES
}

\begin{abstract}
RESUMO: As competências de leitura e escrita no ciberespaço numa época de avanços na área tecnológica apontam para modificações nas formas de ler e escrever em novos suportes e diferentes linguagens. Mediadas pelas tecnologias da informação e comunicação, as leituras e produções textuais são redimensionadas pelas redes sociais. Isso porque, inseridos no ambiente virtual, os internautas estabelecem novas formas de interação, compartilhando informações e experiências, além de desenvolverem novas práticas sociais como a participação ativa em grupos de interesses comuns. $\mathrm{O}$ presente artigo propõe uma reflexão sobre a prática de leitura e escrita na rede Skoob, uma plataforma de interação social. Para tanto, realizou-se uma análise do gênero discursivo resenha disponibilizado nessa plataforma, verificando-se as características dessa produção nesse espaço relacional.
\end{abstract}

PALAVRAS-CHAVE: Novos letramentos. Leitura e escrita. Resenha. Rede social.

\begin{abstract}
The ability of reading and writing in cyberspace at a time of advances in technology indicates alterations in ways of reading and writing in new media and different languages. Social networks mediated by information and communication technologies redesigned readings and textual productions. This is because, inserted in the virtual environment, Internet users establish new forms of interaction, sharing information and experiences, and building new social practices such as active participation in common interest groups. This article proposes a reflection on the practice of reading and writing in Skoob, a social interaction platform. Therefore, it carried out an analysis of the discursive genre review available on this platform, verifying the characteristics of this production in this relational space.
\end{abstract}

KEYWORDS: New literacies. Reading and writing. Review. Social networking.

\section{Introdução}

Os avanços tecnológicos e o acesso aos bens de consumo por uma grande parte da sociedade modificaram as relações humanas e produziram rupturas de determinados padrões e formas de interação social entre pessoas de diversas idades, classes sociais e de variados lugares por meio do ambiente virtual. $\mathrm{O}$ advento da internet e a necessidade natural do ser humano de interagir em diferentes espaços sociais contribuíram para essas mudanças e para os diferentes modos de produzir sentido e de aprender.

As práticas de escrita e leitura nesse ambiente constituem-se, cada vez mais, em modos de agir e interagir. Bauman (2011), nesse sentido, afirma que os aparelhos eletrônicos tornaram mais aguda a necessidade que os sujeitos têm de se sentirem acompanhados, ou seja, 
a sensação de não se sentir só. A afirmação do autor evidencia como as interações no ciberespaço têm vínculo afetivo e social. Um aparelho celular, por exemplo, está sempre ao alcance da mão e, a todo instante, facilita a interação entre familiares, amigos, grupos sociais ou, até mesmo, entre desconhecidos.

Aparici (2012) afirma que a forma de nos relacionarmos está sendo modificada com as redes sociais na internet. Isso porque para uns a internet é uma maneira de se socializar. Para outros é, além disso, uma forma de construção social que permite interações e conexões de natureza distinta.

Para Spadaro (2013), a internet, com seu contínuo desenvolvimento, está se transformando numa plataforma relacional que deve ser considerada como um conjunto de capacidades tecnológicas para a disseminação e o compartilhamento de informação e conhecimentos, ou seja, não é um aglomerado de locais da web isolados e independentes entre si. Spadaro (2013) acrescenta, a respeito da venda de livros on-line, que os comentários feitos por qualquer pessoa sobre obras lidas é uma prática comum em fóruns adequados que podem direcionar o público por suas amplas críticas. Além disso, simples leitores, isto é, aqueles que não são críticos profissionais, têm a oportunidade de verem suas reflexões publicadas. Isso significa que o ambiente virtual proporciona aos diferentes sujeitos a visibilidade que não teriam de outra forma.

O uso da internet nas relações sociais, por tudo isso, auxilia os sujeitos no desenvolvimento do conhecimento coletivo e do contínuo aprendizado, facilitando a interação do indivíduo como participante ativo das práticas feitas em sociedade, ampliando e disponibilizando $\mathrm{o}$ acesso às informações, gerando $\mathrm{e}$ desenvolvendo inovações $\mathrm{e}$ compartilhando ideias.

Tendo em vista o dinamismo do mundo contemporâneo na utilização do ciberespaço como local de interação social, quais mudanças esse novo espaço propõe aos modos de ler, de escrever e de se relacionar? Como as novas tecnologias motivam e determinam o uso crescente das redes sociais como ambiente de interação entre as pessoas? Como as ferramentas criadas para a prática de leitura e escrita podem ser utilizadas na aprendizagem? Buscando refletir sobre esses questionamentos, o presente artigo analisará práticas de leitura e escrita utilizadas no ambiente virtual, mais propriamente a rede social Skoob como ferramenta de interação entre os internautas que possuem um interesse comum: a leitura de livros e o 
compartilhamento de informações de leitura por meio da produção e divulgação do gênero discursivo resenha.

Para tanto, este artigo fará uma breve retomada teórica sobre tecnologia, gêneros discursivos e práticas de leitura e escrita em ambientes virtuais. Para a análise, foram selecionadas três resenhas disponíveis no skoob, considerando-se como os textos selecionados estão construídos. A opção de pesquisar a produção escrita nessa rede social deve-se à emergência de se explorar o uso do ambiente virtual no processo de ensino-aprendizagem como ferramenta para os novos letramentos.

\section{Tecnologia e Linguagem: modos de ler e escrever - da folha de papel à tela de aparelhos eletrônicos}

A contemporaneidade é caracterizada pela diversidade de informações, pela pluralidade de textos disponíveis a um número cada vez maior de pessoas. Essas informações podem ser compartilhadas, muitas vezes, por um simples toque da tela de um dispositivo móvel.

Nesse contexto, as práticas de leitura e escrita ganham novos contornos e acionam, cada vez mais, estratégias e gêneros discursivos diferenciados. Marinho e Carvalho (2010) afirmam que, com as novas tecnologias, surgiram ambientes originais para interação; e gêneros discursivos e formatos tradicionais no impresso se renovaram, ganhando novas características como aconteceu, por exemplo, com o surgimento dos e-mails e os blogs, antes cartas, bilhetes e diários.

Esses ambientes interacionais propõem novas formas de expressão, novas maneiras ou velhas maneiras renovadas de produção - no caso, a oral e a escrita -, novos processos cognitivos e, consequentemente, novas propostas de aprendizagem. Disso é o que trata Rojo (2013), ao dizer que "novos escritos" dão lugar a novos gêneros discursivos em consequências das novas tecnologias e ferramentas de "leitura-escrita", hoje disponíveis, convocando novos letramentos. Andersen (2013) afirma que a internet dispõe de ferramentas de ampliação e enriquecimento interacional/colaborativo entre as pessoas e que, aplicadas à aprendizagem, esses instrumentos interacionais criam um espaço de possibilidades que facilitam o aprendizado. 
Soma-se a isso, a diversidade de produtos existentes no mercado que permitem o acesso ao ciberespaço como computadores, tablets, televisores modernos com acesso à internet - as smartTVs - e aparelhos celulares que favorecem o uso, cada vez mais frequente, de plataformas sociais para as práticas de leitura e escrita. Nesse sentido, Chartier esclarece que os primeiros leitores eletrônicos verdadeiros não passam mais pelo papel:

\begin{abstract}
Nas experiências que foram feitas em torno da Biblioteca Nacional da França, envolvendo uma população de estudiosos ou grandes leitores profissionais, pôde-se observar que alguns dentre eles liam diretamente na tela as informações e os textos armazenados na memória de seu computador. Nos Estados Unidos, vê-se mesmo desenvolver a prática da leitura de conferências na tela do computador portátil, aberto pelo conferencista como era o caderno ou a pasta de papéis. Isto define uma figura do leitor futuro? Talvez. (1988, p 37)
\end{abstract}

As telas também são suportes utilizados para a produção textual escrita. Esse ambiente virtual contribui para modificações nos gêneros discursivos, pois a produção de leitura e escrita é realizada, na maioria das vezes, sem mediadores, ou seja, não há nenhum tipo de orientação sobre os usos da língua que venha evitar a variação. A esse respeito, Marcuschi comenta que:

(...) nos bate-papos virtuais abertos, são construídas identidades sociais muitos diversas das que se constroem nas conversações face a face. Esse aspecto não está nos domínios de controle de nenhum engenheiro de software. $\mathrm{O}$ engenheiro pode, quando muito, controlar a ferramenta conceitual, mas não os usos e, muito menos os usuários. (2008, p. 71)

Para Marcuschi (2008), deve-se considerar o meio pelo qual ocorrem essas mudanças, pois é do meio tecnológico que provêm as interações altamente participativas entre os indivíduos, que interferem na natureza do gênero produzido e propõe uma reflexão a respeito da transposição da comunicação feita entre os ambientes físico e virtual, ou seja, sobre a mudança existente entre a relação de uma conversa face a face para a de um bate papo online aberto, isto é, o momento em que a relação interpessoal passa a ser hiperpessoal. A questão levantada por Marcuschi aponta para a mudança composicional dos gêneros, considerando as situações sociais como tempo, espaço, objetivo, enunciador e destinatário. Considerando todos esses aspectos das situações dialógicas, as interações sociais no ciberespaço ocorrem por meio das práticas orais e escritas quer sejam por vídeos quer sejam por gêneros textuais escritos como as resenhas e os comentários. 
As mudanças geradas pelo meio tecnológico são significativas, sobretudo, do ponto de vista:

- histórico-social: considerando a situação socioeconômica do país numa necessidade de se modernizar e de proporcionar à população o acesso aos recursos tecnológicos como, por exemplo, a implantação das TVs pendrive em escolas públicas;

- cultural: considerando, por exemplo, a cultura empresarial de hoje, fazer conferências, entrevistas e até mesmo trabalhar em casa por meio da interação online;

- cognitivo: considerando as novas formas de aprender, como por exemplo as aulas em vídeo, os cursos on-line, etc.

Marcuschi (2008) assevera que as práticas comunicativas, especificamente a fala e a escrita, são atividades situacionais, cujo contexto de produção - cognitivo, cultural, social e histórico - é parte integral do ato de falar e escrever. Para o autor, as produções de um texto sob certas condições pode, em outro contexto de recepção, ter outra condição de recepção. Dessa forma, Marcuschi evidencia as mudanças de produção e recepção de textos, sendo esses, pois, históricos.

Bauman (2011, p. 8), nessa perspectiva, aponta para consideráveis mudanças ao dizer que “ [...] o que é apropriado no dia de hoje pode não sê-lo amanhã”. Isso porque, segundo o autor, o mundo está constantemente sujeito às modificações. De forma contínua e rápida, a sociedade contemporânea está cercada por uma enxurrada de informações provindas da internet e da web, definidas por ele como "autoestradas de informação", que conectam as pessoas rapidamente em qualquer canto do planeta por meio de dispositivos eletrônicos, a qualquer momento e em qualquer lugar. Coisas que as gerações anteriores nem podiam imaginar.

Sobre essas modificações nos hábitos de leitura e escrita na história das civilizações, Chartier afirma que:

Os gestos mudam segundo os tempos e lugares, os objetos lidos e as razões de ler. Novas atitudes são inventadas, outras se extinguem. Do rolo antigo ao códex medieval, do livro impresso ao texto eletrônico, várias rupturas maiores dividem a longa história das maneiras de ler. Elas colocam em jogo a relação entre o corpo e o livro, os possíveis usos da escrita e as categorias intelectuais que asseguram sua compreensão. (1988, p. 89)

A respeito da recepção de textos, considerando-se o contexto de produção e o contexto de uso - espaço e tempo -, Lévy (1999) trata da possibilidade de leitura equivocada 
de uma mensagem escrita há cinco séculos ou redigida à distância de cinco mil quilômetros. Entretanto, segundo o autor, algumas mensagens foram concebidas a fim de preservar o sentido, independentemente do contexto de recepção, que ele denomina como mensagens "universais". O autor, no entanto, levanta a hipótese de que a cibercultura direciona-se a uma nova universalidade que adquire sentidos variados e renovação permanente por meio das comunidades virtuais.

Essas dificuldades trazidas pelos contextos - produção e uso - também são exploradas por Koch e Elias (2006), ao alertarem que a distância temporal entre a produção do texto escrito e a sua leitura pode interferir na produção de sentido feita pelo sujeito no momento da leitura. Porém, considerando-se os recursos tecnológicos da atualidade com hipermídias que possibilitam os acessos simultâneos a textos, imagens e sons, esses recursos podem ser utilizados como facilitadores à produção de sentido de um texto.

Chartier (1998), a respeito desses recursos hipermidiáticos e do texto eletrônico, argumenta que, no mesmo suporte, o texto, a imagem e o som podem ser conservados e transmitidos, apreendendo por meio de diferentes figuras, de sua descrição, de sua representação e de sua presença, toda a realidade do mundo sensível.

Assim, as mudanças nas práticas contemporâneas de leitura e escrita por meio dos recursos tecnológicos, ou seja, do papel à tela dos dispositivos eletrônicos, apontam para reflexões acerca da valorização que tais práticas possuem para o processo de ensinoaprendizagem no sentido de apresentar outros modos de significação de um texto, de sua compreensão. Marinho e Carvalho (2010) argumentam que novas formas de leitura e escrita são trazidas pelas novas tecnologias com instrumentos de leitura e produção de textos hipermidiáticos. Esses instrumentos permitem a diversificação de textos verbais e não verbais com outros elementos multimodais de significação, como efeitos de imagem e som, cinestesia etc. Rojo (2013, p. 20), nesse sentido, esclarece que "hoje dispomos de novas tecnologias e ferramentas de 'leitura-escrita', que, convocando novos letramentos, configuram os enunciados/textos em sua multissemiose ou em sua multiplicidade de modos de significar."

À vista disso, Lopes (2013), ao fazer uma abordagem sobre os livros didáticos digitais interativos, aponta para as características multimodais, midiáticas, intuitivas e interativas desses livros que facilitam muito a compreensão e análise de conceitos, antes abstratos e longínquos, de linguagem verbal escrita altamente complexa. Para o autor, os objetos e as animações interativas, as imagens estáticas e em movimento, os áudios e os 
vídeos, etc. presentes nos LDDIs ${ }^{1}$ são meios para a compreensão de conceitos e interação com o texto. Portanto, são novas formas de produzir sentido para os textos da contemporaneidade.

\section{As interações sociais na plataforma Skoob}

Nos últimos anos, houve a ampliação do acesso às redes sociais, assim como um aumento significativo na criação de aplicativos que possibilitam a interação entre diferentes sujeitos e grupos sociais. Esse acesso facilitado produz diversas formas de expressão e evidenciam um desejo de visibilidade e atenção por parte dos sujeitos.

Nesse sentido, Spadaro (2013) comenta que a disponibilidade de um instrumento como o blog, por sua flexibilidade, traz ao internauta a vontade de receber atenção, de ser visto, de querer falar. Para Aparici (2012, p. 91), as redes estão compostas por indivíduos com os mesmos interesses e conhecimentos e funcionam segundo o princípio de que pessoas, grupos, sistemas e entidades podem criar uma totalidade integrada em que a noção de coincidência e criatividade por meio de ideias e campos diferentes pode produzir inovações.

Dentre as redes sociais direcionadas a um público específico, está o $\mathrm{Skoob}^{2}$, uma plataforma de comunicação digital, um espaço de interação entre os internautas cujos usuários possuem interesses comuns entre si, pois é uma rede voltada para leitores de livros em todo o Brasil. A plataforma possibilita a montagem de uma estante virtual, além de armazenar informações sobre variadas obras. A rede possui milhares de usuários cadastrados que a utilizam para compartilhar informações e experiências sobre livros lidos ou para obter informações acerca de obras que se pretende ler, interagindo com outras pessoas - os chamados skoobers - de diversos lugares do país e com diferentes opiniões. O Skoob pode ser baixado em forma de aplicativo em aparelhos celulares e interage com outras plataformas como Facebook, Twitter, Instagram e Google Plus.

\footnotetext{
${ }^{1}$ LDDIs - livros didáticos digitais interativos

${ }^{2}$ A rede está disponível em: http://www.skoob.com.br. Acesso em 15.03.2015
} 


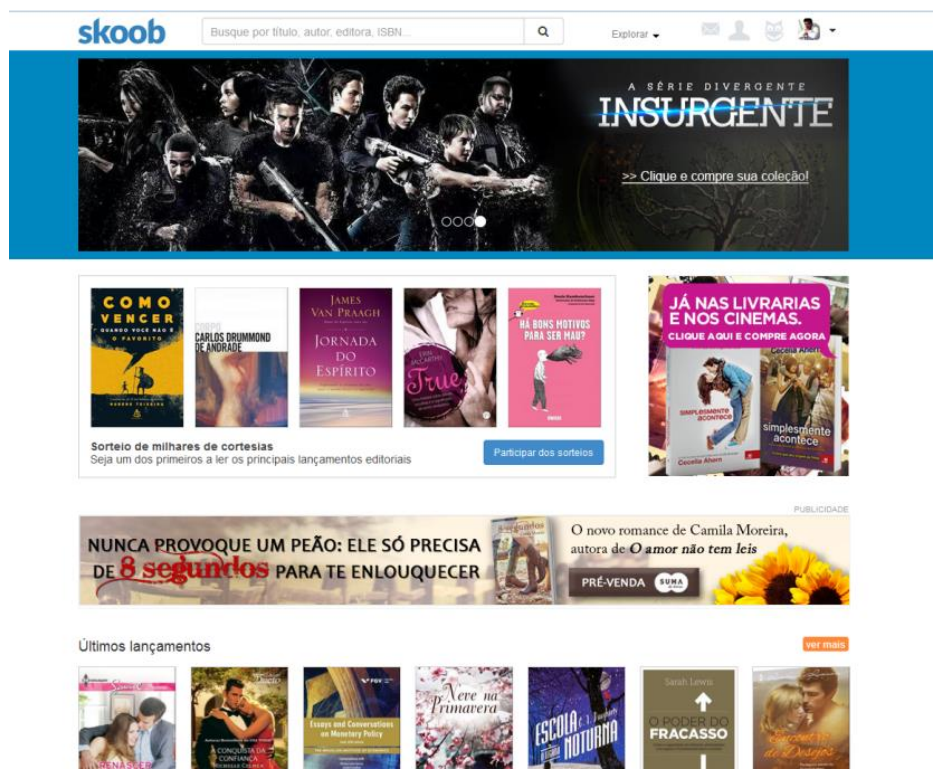

Figura 1 - Interface da rede social Skoob - página principal ${ }^{3}$

O Skoob foi criado em 2009 por Lindenberg Moreira e Viviane Lordello ${ }^{4}$. A ideia da criação da rede surgiu por uma necessidade dos amigos de ter uma alternativa online para falarem acerca das experiências de leituras. Segundo informa o próprio site, é uma das redes mais utilizadas no Brasil com mais de dois milhões de usuários. Além do compartilhamento e discussão sobre livros, os internautas cadastrados podem fazer aquisição, troca de obras e participar de sorteios.

A rede Skoob possui interface de natureza multimodal com variadas linguagens, diversificação das suas ferramentas e recursos. Os usuários podem:

- por meio de imagens: visualizar as obras e verificar informações sobre a publicação;

- por meio de janelas: marcar opções para obras lidas, para as que está lendo, para as que deseja ler, para as que estão sendo relidas e para aquelas cuja leitura foi abandonada, além de fazer comparação de preços entre diversas livrarias;

- por meio de ícones: classificar obras, marcar como lidas ou desejadas para leitura futura, informar quais livros possui, quais estão emprestados e quais podem ser trocados.

Além desses recursos, a rede disponibiliza, de forma dinâmica, o acesso à sinopse, às edições, a vídeos, aos grupos, às resenhas, aos leitores, às obras similares e aos textos em

\footnotetext{
${ }^{3}$ Fonte: Disponível em: www.skoob.com.br. Acesso em: 22/03/2015.

${ }^{4}$ Informações disponíveis em: www.skoob.com.br. Acesso em: 22/03/2015
} 
PDF. Apresenta ainda uma estatística, em números percentuais, das avaliações feitas por homens e mulheres acerca dos livros lidos.

O Skoob é uma plataforma de interação de conhecimento coletivo, mas que permite aos usuários a construção individual e crítica na elaboração de textos opinativos. Os textos produzidos pelos próprios internautas constituem-se em uma forma de interação que possibilita o compartilhamento de conhecimentos, reflexões e análises sobre as obras lidas, disponibilizando informações que podem ser visualizadas pelos usuários cadastrados na rede ou pelos visitantes. Outra forma de interação apresenta-se nos comentários em que os participantes, de forma colaborativa, apresentam opiniões, como mostra a figura abaixo:

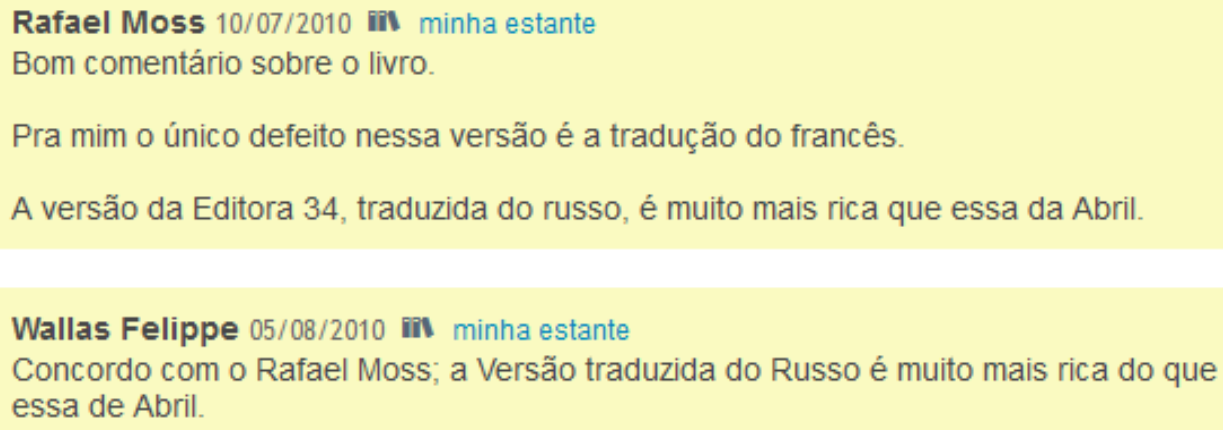

Figura 2 - Ferramentas do Skoob - produção textual: comentários 5

A rede social Skoob, portanto, proporciona aos internautas uma prática de leitura e escrita mais interativa e atrativa em que os skoobers podem se expressar, além de possibilitar a visibilidade desses sujeitos, uma vez que os textos postados podem ser vistos por quaisquer internautas que visitem o site.

\section{O gênero resenha na rede social Skoob}

Para Bakhtin (2003), a enunciação configura-se no uso da língua como forma de interagir em sociedade, de se comunicar, ou seja, a comunicação, na concepção bakhtiniana, tem caráter social e constitui-se em uma atividade que se realiza por meio de enunciados com características relacionadas a situações sociais. Assim, a enunciação é perpassada por

\footnotetext{
${ }^{5}$ Fonte: www.skoob.com.br. Acesso em 25.03.2015
} 
diferentes concepções políticas e ideológicas, que constituem o sujeito socialmente situado. Essa interação considera um conjunto de discursos que circulam socialmente. Tais enunciados são marcados por outros que o precedem, ou seja, todo enunciado reflete características discursivas de enunciados já produzidos anteriormente.

Baseado nessa relação entre a língua e as diversas atividades sociais com as quais a língua se relaciona, Bakhtin (2003) postula a noção de gêneros discursivos. Para o autor, cada área do conhecimento possui formas características de uso da língua, diferentes tipos de enunciados que apresentam temática, estilo e composição peculiares. Cada esfera de atividade elabora esses tipos relativamente estáveis de enunciados, que se desenvolvem à proporção que a esfera de atividade se amplia. Disso provém a riqueza e diversidade dos gêneros discursivos que, segundo o autor, são infinitas, pois as possibilidades da multiforme atividade humana são inesgotáveis.

Para Bakhtin,

A riqueza e a variedade dos gêneros do discurso são infinitas, pois a variedade virtual da atividade humana é inesgotável, e cada esfera dessa atividade comporta um repertório de gêneros do discurso que vai diferenciando-se e ampliando-se à medida que a própria esfera se desenvolve e fica mais complexa. (2010, p. 279)

Os gêneros são definidos por seu conteúdo temático, pelo estilo da linguagem, isto é, pela seleção dos recursos lexicais, fraseológicos e gramaticais da língua, e por sua construção composicional relativamente estável. Assim, não basta dominar o código da língua para dominar os gêneros textuais, pois faz-se necessário também conhecer a esfera na qual esses gêneros circulam. Para Brait e Pistori (2012), o conceito de gênero ultrapassa a materialidade e a estrutura do texto, ainda que considere fundamentais esses aspectos, sugere dialogismo e modos de compreender e enfrentar a vida.

A respeito da produção escrita dos gêneros, Antunes (2004) argumenta que, assim como a fala não é uniforme, a forma de escrever um texto também varia devido à função que se pretende cumprir e aos diferentes gêneros discursivos em que se realiza. $\mathrm{O}$ texto tem uma superestrutura que varia em sua distribuição, organização e apresentação em partes ou blocos mais ou menos estáveis, numa ordem mais ou menos fixa.

Conforme a autora, os gêneros discursivos se manifestam como resultados de convenções históricas e sociais instituídas por pessoas que também são autoras dos textos. São essas mesmas pessoas que criam as convenções e as modificam ou as ignoram sempre 
que necessário. Portanto, os gêneros discursivos evidenciam, para Antunes (2004), uma natureza complexa das realizações linguísticas, sendo, por um lado regida por modelos e padrões e, por outro, passível de alterações.

Antunes (2005, p. 37), ao afirmar que “ [...] uma carta, um requerimento, uma ata, uma declaração, um comentário, uma notícia, um aviso, por exemplo, não começam do mesmo jeito, não se desenvolvem e se fecham sob o mesmo modelo", propõe a flexibilidade dos gêneros discursivos. A autora afirma ainda que há esquemas típicos para cada um deles, sendo uns mais rígidos que outros. Nesse sentido, Bakhtin (2003, p. 265) enfatiza a importância do enunciado para a vida social ao dizer: "Ora, a língua passa a integrar a vida através de enunciados concretos (que a realizam); é igualmente através de enunciados concretos que a vida entra na língua”.

Considerando essa concepção, este artigo propõe uma reflexão sobre a prática de escrita na rede Skoob. Para tanto, toma como objeto de análise o gênero discursivo resenha disponibilizado nessa plataforma. Interessa-nos investigar a produção do gênero resenha pelos usuários da rede, estabelecendo relações entre as características da macroestrutura do gênero e a produção livre desenvolvida pelos usuários da rede.

Segundo Machado, Lousada e Abreu-Tardelli (2007), o gênero discursivo resenha se constitui da apresentação e resumo de uma opinião pessoal, de forma argumentada sobre o conteúdo de determinado texto lido. Portanto, ao transmitir um ponto de vista particular, manifestado por meio de argumentações, pressupõe-se que o resenhista tenha feito uma leitura atenta do texto original para sua sustentação e fundamentação. Esse gênero requer, portanto, dois conhecimentos fundamentais para sua produção: o do gênero e o do objeto a ser resenhado.

Ao diferenciar resenha de resumo, as autoras definem que há textos que são caracterizados pelas informações selecionadas e resumidas a respeito do conteúdo de outro texto. Esses são os resumos. Contudo, há também textos que, além de apresentarem as características do resumo, apresentam também comentários e avaliações. Esses são as resenhas.

Para Köche, Boff e Pavani (2008), as resenhas podem ser descritivas ou críticas, sendo esta a que apresenta o julgamento ou a apreciação do resenhista. Ao descrever as etapas de uma resenha crítica de uma obra ou de um artigo, as autoras afirmam que ela é constituída 
sinteticamente de: identificação, apresentação, descrição, avaliação, recomendação, dados do autor e assinatura do resenhista.

Uma resenha de um livro, conforme Machado, Lousada e Abreu-Tardelli (2007), é estruturada da seguinte forma: primeiramente, deve conter informações sobre o contexto e o tema do livro resenhado; depois, o(s) objetivo (s) da obra resenhada; em seguida, a descrição estrutural da obra que pode ser feito por capítulos ou seus agrupamentos; após, devem ser apontados os comentários do autor da resenha, seguidos da sua apreciação que podem ser de comentários tanto positivos quanto negativos; e, por fim, a conclusão em que se deve explicitar/reafirmar o posicionamento do resenhista em relação ao livro resenhado.

Sobre o uso dos organizadores textuais, as autoras enfatizam a importância da utilização dos conectivos em um texto cujas funções podem ser atribuídas para estabelecer relações não só entre parágrafos e frases, mas também entre ideias por meio de conectivos que indicam sua adição, seu contraste ou argumentos contrários e ainda conectivos que indicam explicação, constatação ou confirmação. Esses conectores são necessários em uma resenha para organizá-la, para que seja clara e coerente ao leitor.

Sobre os comentários opinativos, Machado, Lousada e Abreu-Tardelli (2007) sugerem algumas regras de polidez por meio de palavras e expressões que atenuam as opiniões. Assim, alguns recursos linguísticos podem ser empregados, tais como os tempos verbais que assumem a função de atenuadores ao que está sendo dito, como por exemplo, o futuro do pretérito. Algumas classes de palavras, como adjetivos, substantivos e advérbios também podem ter essa mesma função no texto.

Além da utilização do gênero em redes sociais voltadas à interação de um público específico, como o Skoob, a resenha também é utilizada em sites de jornais e revistas como o site do Estadão ${ }^{6}$ e da Veja ${ }^{7}$, porém, a diferença existente nas produções das resenhas feitas na plataforma Skoob em relação as que são produzidas em mídias jornalísticas da internet é que, nestas, a escrita não é feita por qualquer internauta. Ou seja, os leitores das páginas online do jornal e da revista não participam da produção escrita. Isso significa que não há uma colaboração ampla, livre e aberta na produção textual do gênero resenha. A participação dos internautas ocorre somente por meio de comentários.

É por meio da resenha e dos comentários que ocorre a participação colaborativa na rede social Skoob, mas é por intermédio da resenha que os skoobers contribuem mais

\footnotetext{
${ }^{6}$ Disponível em: http://topicos.estadao.com.br/resenha. Acesso em: 29/03/2015.

${ }^{7}$ Disponível em: http://veja.abril.com.br/idade/oscar/resenhas.html. Acesso em: 29/03/2015.
} 
especificamente com outros internautas que necessitam de detalhes a respeito das obras, oferecendo informações acerca das experiências de leitura, expondo suas opiniões e críticas. Dessa forma, muitos usuários interessam-se pela leitura de certos livros devido às impressões expressas nas resenhas.

Ao iniciar a escrita de uma resenha na rede skoob, a ferramenta possui um espaço para que o usuário coloque título e também sugere que o skoober escreva o que achou do livro ou o que aprendeu com ele. Se desejar compartilhar o texto escrito, o resenhista poderá fazêlo, enviando a resenha para o twitter, para o facebook ou para ambos.

Entretanto, vale ressaltar que muitas produções escritas, sobretudo no ambiente virtual, não configuram especificamente o gênero. Muitos textos caracterizam-se como resumos e outros constituem-se apenas de comentários. Essa inconsistência na produção da resenha pode ser constatada na plataforma Skoob.

Para a análise, foram selecionadas três resenhas diferenciadas, considerando as características já elencadas a fim de verificar se elas estão presentes nos textos selecionados.

Texto 1:

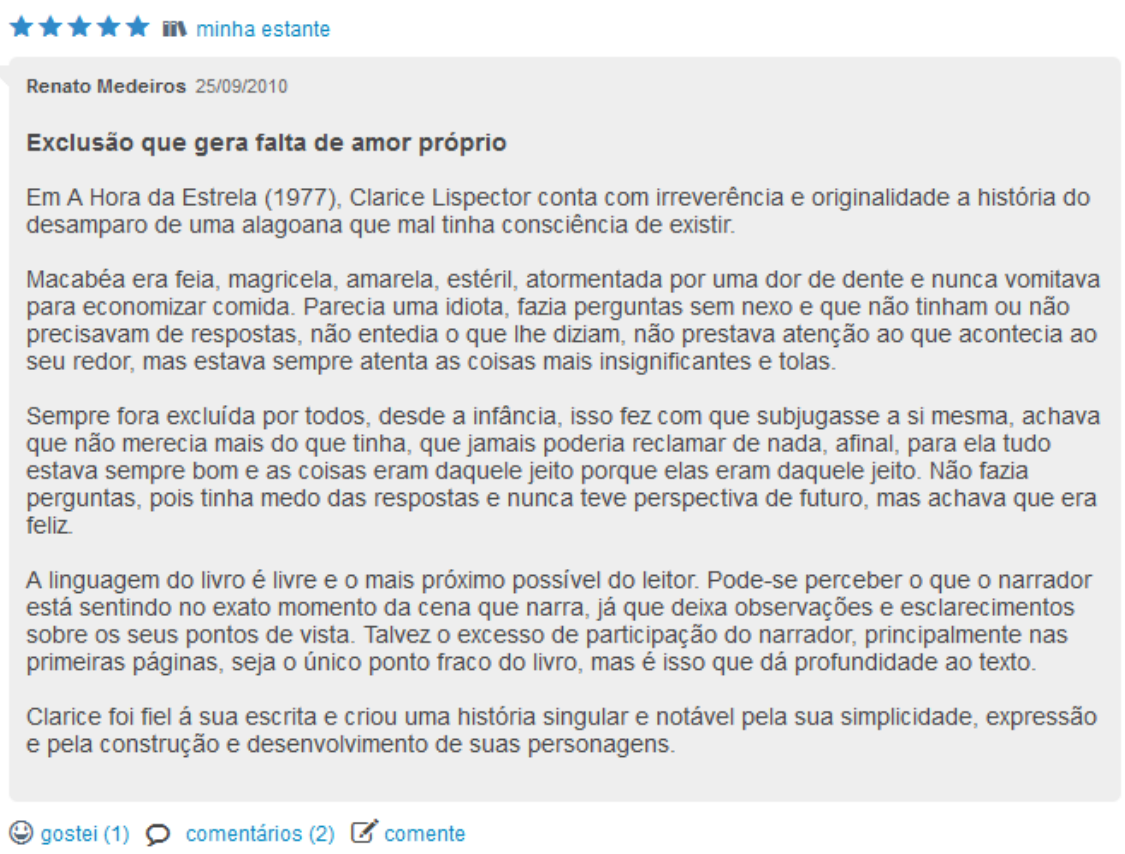

Figura 3 - Resenha do livro: A hora da Estrela ${ }^{8}$

\footnotetext{
${ }^{8}$ Fonte: Disponível em: http://www.skoob.com.br/livro/resenhas/183/edicao:268. Acesso em: 22/03/2015.
} 
O texto 1 possui título, data de publicação, nome da autora, resumo e avaliação, ou seja, verifica-se a presença de aspectos fundamentais da resenha como identificação, apresentação, descrição, avaliação. O texto está estruturado em cinco partes, sendo a primeira composta pelo tema/título: "Exclusão que gera falta de amor próprio" e contexto no primeiro parágrafo: "a história do desamparo de uma alagoana"; seguida pela descrição da obra no segundo e terceiro parágrafos; depois, o autor apresenta uma avaliação do livro no quarto parágrafo; no último, o resenhista faz uma apreciação sobre a autora e, finaliza, reafirmando seu posicionamento.

É possível perceber marcas de subjetividade por meio de adjetivos em que o resenhista expressa sua opinião a respeito da história criada pela autora, utilizando, por exemplo, as palavras "singular" e "notável". Embora não explore a coesão de forma elaborada, ocorre a presença de conectivos que indicam adição (e) e contraste (mas), evidenciando a articulação argumentativa do texto. Ocorrem, também, apreciações positivas a respeito da obra, por meio de palavras como: "simplicidade", "expressão" etc. O emprego de alguns advérbios, tais como "mais" marcam a voz opinativa do autor ao mesmo tempo que o "talvez" expressa polidez, atenuando a opinião. Embora o texto esteja em terceira pessoa, verifica-se posicionamentos críticos sobre a obra. O nome do autor e a data da publicação do texto são inseridos pela própria ferramenta Skoob.

A análise do texto, por tudo isso, revela marcas de estilo e conteúdo composicional que o caracterizam como do gênero resenha, e o aproxima do modelo estrutural de resenha proposto por Machado, Lousada e Abreu-Tardelli (2007). Verifica-se também que o texto se aproxima da variante padrão da Língua Portuguesa, pois há poucos desvios da norma culta que são comuns em textos produzidos na internet em que a produção não é monitorada.

Para a segunda análise, foi selecionada uma produção menor, mas com características recorrentes na rede Skoob:

Texto 2:

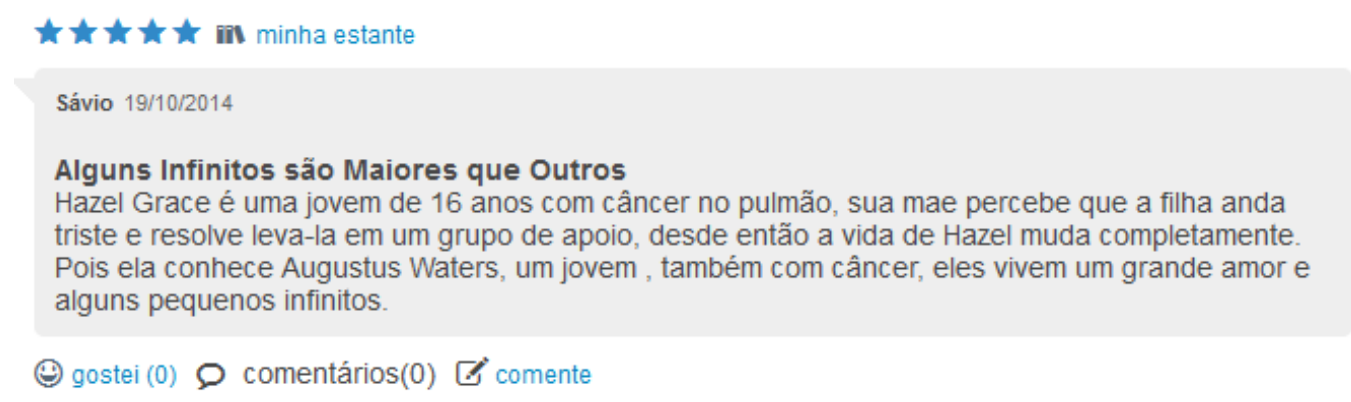


Figura 4 - Resenha do livro: A culpa é das estrelas ${ }^{9}$

O texto II caracteriza-se por sequências narrativas e descritivas em que o autor apresenta uma breve síntese cronológica da história da obra. Diante das considerações feitas sobre as aproximações entre resumo e resenha, verifica-se a presença das características de um resumo. $\mathrm{O}$ autor não expõe quaisquer julgamentos ou apreciações a respeito da obra e não há conectivos que indicam contraste de ideias ou argumentos. O resenhista deteve-se apenas às informações limitadas sobre o enredo.

Ocorre o predomínio de sequências descritivas que aproximam o texto do gênero sinopse, com um breve roteiro sequencial dos acontecimentos. Há inadequações no texto pelo uso não padrão da língua, comuns em produções feitas no ambiente virtual sem monitoramento, como por exemplos, na palavra "mae" que não possui o sinal gráfico "til" e no verbo "levar" seguido do pronome "la" que não está acentuado como prescreve a regra de acentuação das palavras oxítonas pela gramática normativa. Além disso, há uso excessivo da vírgula, que prejudica a fluidez da leitura, e uso inadequado do ponto final, que interrompe uma explicação iniciada pelo conectivo (pois).

A repetição da expressão "com câncer" em "também com câncer" num intervalo pequeno na utilização entre ambas aproxima a escrita ao que ocorre na fala em situações informais, ou seja, é uma marca da oralidade no discurso. Uma justificativa para essas inadequações é apresentada por Marcuschi (2008, p. 72) que, ao falar sobre os gêneros mais praticados no ambiente virtual, afirma que a comunicação se dá pela linguagem escrita. Esta, segundo o autor, "[...]tende a uma certa informalidade, menor monitoração e cobrança pela fluidez do meio e pela rapidez do tempo.".

A análise mostra que o texto II possui características de outro gênero discursivo, o resumo, além de algumas inadequações de produção textual no que diz respeito à norma padrão da língua, ou seja, embora seja nomeado como resenha, não se constitui em uma devido à ausência de aspectos estruturais essenciais.

O último texto selecionado para análise neste artigo também possui extensão recorrente na rede Skoob:

Texto III:

\footnotetext{
${ }^{9}$ Fonte: Disponível em: http://www.skoob.com.br/livro/resenhas/247555/edicao:277187. Acesso em: $22 / 03 / 2015$.
} 


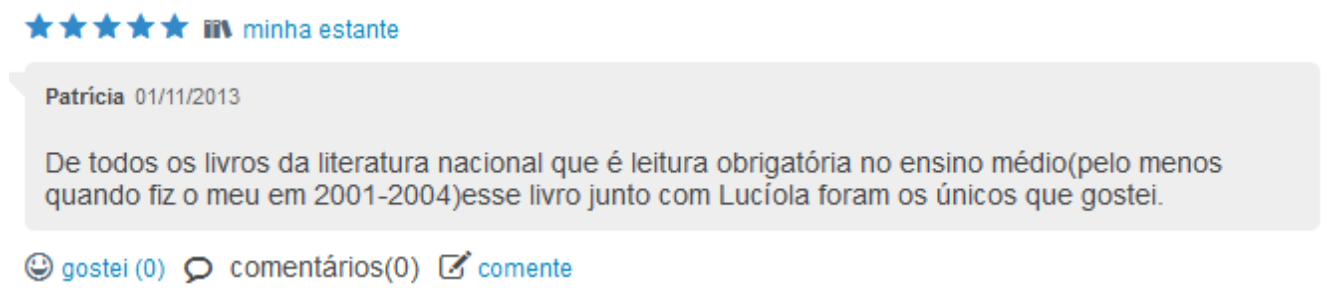

Figura 5 - Resenha do livro: Triste Fim de Policarpo Quaresma ${ }^{10}$

O Texto III constitui-se em um breve comentário, pois expõe apenas um ponto de vista da autora em relação a determinadas obras: "leitura obrigatória no ensino médio", além de trazer uma opinião pessoal acerca delas: "foram os únicos que gostei” sem fundamentar tal posicionamento. Sobre isso, as autoras Köche, Boff e Pavani (2008), argumentam que julgamentos que não são justificados pela razão, ou seja, aqueles que exprimem apenas o sentimento do autor, devem ser evitados na elaboração de uma resenha, tais como os que vêm precedidos ou antecedidos pelas expressões: “eu gosto” ou “eu não gosto”. Machado, Lousada e Abreu-Tardelli (2007) explicam que é comum o resenhista evitar escrever em primeira pessoa, embora expresse sua subjetividade de modo a garantir veracidade ao comentário do autor sem que o leitor perceba claramente que a opinião é de um resenhista. Entretanto, no Texto III, os verbos "fiz" e "gostei" marcam a autoria do texto e expressam a opinião explícita da resenhista.

Além de o texto não apresentar as características do gênero resenha, acrescenta informações que não estão previstas pelo leitor da resenha como, por exemplo, a obra ser leitura obrigatória no ensino médio. O texto também não apresenta conectivos que introduzem argumentos, causas, justificativas ou conclusões. O texto ainda não traz nenhuma referência ao leitor sobre a obra lida, exceto que o livro pertence à literatura nacional. Verifica-se também o desvio da norma padrão como, por exemplo, o apagamento da preposição do verbo gostar (de).

As produções textuais dos internautas analisadas acima explicitam uma variação na produção de diferentes textos que ora se constituem no gênero resenha por suas características composicionais e estilísticas, ora se distanciam. A análise evidencia que não há, na prática de escrita na plataforma Skoob, uma apropriação do conhecimento composicional ou estilístico desse gênero discursivo pelos usuários da rede, os skoobers, pois as produções diferenciam-se

\footnotetext{
${ }^{10}$ Fonte: Disponível em: http://www.skoob.com.br/livro/resenhas/695/edicao:88928. Acesso em: 22/03/2015.
} 
quanto à sua construção com estruturas e características diversas. Portanto, a análise dessas produções revela movimentos de simplificação, característicos desse meio, ao mesmo tempo que lançam desafios para os novos letramentos na utilização dos recursos disponibilizados no ambiente virtual para o processo de ensino-aprendizagem dos gêneros discursivos.

\section{Considerações Finais}

Os textos da contemporaneidade apresentam recursos mais atrativos e interativos, diversificando-se na forma e no conteúdo com elementos de natureza multimodal que convocam novos letramentos. Os sujeitos, nesse contexto, são atravessados por demandas sociais de participação e comunicação diretamente relacionadas aos novos letramentos como, por exemplo, a apropriação de recursos tecnológicos para a prática de leitura e de escrita. À medida que surgem novas tecnologias, novas formas de ler, de escrever e de se relacionar vão se constituindo. Os avanços tecnológicos contribuem para mudanças significativas dessas práticas no ciberespaço.

Os ambientes interacionais oferecem novas formas de expressão do sujeito, maneiras distintas de produção de leitura e de escrita que acionam novos processos cognitivos e propostas renovadas de aprendizagem. Por um lado, o ambiente virtual oferece ferramentas de ampliação do saber individual/coletivo e propõe atividades interacionais/colaborativas entre as pessoas. Esses instrumentos redimensionam o espaço de possibilidades que facilitam o aprendizado. Por outro lado, o não monitoramento nas produções, sobretudo escritas, realizadas nesse ambiente, favorece desvios na utilização dos gêneros discursivos.

Nas três produções textuais analisadas neste artigo, apenas uma (Texto I) se constitui conforme o gênero resenha, ao apresentar conteúdo temático e estilo de linguagem característicos desse gênero, com apresentação e resumo de uma opinião pessoal, de forma argumentada sobre o conteúdo do texto lido. Os Textos II e III variam entre o gênero resumo e comentário breve, ou seja, não se constituem em uma resenha, pois há a ausência de elementos mínimos caracterizadores desse gênero.

Assim como as redes sociais existentes hoje, o Skoob é uma plataforma interacional que estimula a leitura e a produção escrita, pois é direcionada ao público leitor em que o usuário cadastrado tem a oportunidade de transmitir, por meio do gênero discursivo resenha, suas apreciações sobre as obras lidas. A análise das produções escritas revela, entretanto, 
inadequações e explicita a necessidade de ampliação do trabalho com o gênero resenha para qualificar a produção dos internautas. Uma possibilidade seria a própria rede Skoob disponibilizar aos seus usuários critérios para a produção e publicação desses textos.

Contudo, faz-se necessário destacar que em tempos de web 2.0 que tem como uma de suas características principais a interação e participação, estabelecer critérios para a produção e publicação poderia limitar a participação dos internautas e gerar um número menor de acessos à rede.

O outro aspecto a ser levantado é que, embora a resenha seja um gênero de circulação na esfera acadêmica, tanto na educação básica (anos finais), quanto na universidade, o trabalho pedagógico com esse gênero precisa ser mais sistematizado a fim de contribuir para o desenvolvimento de capacidades de leitura e escrita que envolvam o resumo de ideias principais e de apreciação crítica sobre os textos lidos. Tal abordagem aproxima as práticas escolares de leitura e escrita das atividades concretas desenvolvidas pelos diferentes sujeitos em suas práticas sociais de comunicação.

\section{Referências Bibliográficas}

ANDERSEN, Elenice Larroza. Multimídia digital na escola. São Paulo: Paulinas, 2013. ANTUNES, Irandé. Aula de português: encontro \& interação. $2^{a}$ ed. São Paulo: Parábola, 2004.

Lutar com palavras: coesão e coerência. $3^{\mathrm{a}}$ ed. São Paulo: Parábola, 2005.

BAKHTIN, Mikhail. Estética da criação verbal. $4^{\mathrm{a}}$ ed., São Paulo: Martins Fontes, 2003. . Marxismo e Filosofia da Linguagem. 14a ed. São Paulo: Hucitec, 2010.

BAUMAN, Zygmunt. 44 cartas do mundo líquido moderno. Tradução Vera Pereira. Rio de Janeiro: Zahar, 2011.

BRAIT, Beth e PISTORI, Maria Helena Cruz. A produtividade do conceito de gênero em Bakhtin e o Círculo. In: Alfa, São Paulo, 56 (2): 371-401, 2012.

LÉVY, Pierre. Cibercultura. Tradução de Carlos Irineu da Costa. São Paulo: Editora 34, 1999

LOPES, Luiz Paulo da Moita. Linguística aplicada na modernidade recente: festschrift para Antonieta Celani. 1. ed. São Paulo: Parábola, 2013, p. 189-190. 
MACHADO, Anna Rachel; LOUSADA, Eliane Gouvêa; ABREU-TARDELLI, Lília Santos. Resenha. São Paulo: Parábola Editorial, 2004

MARCUSCHI, Luiz Antônio. Produção Textual, análise de gêneros e compreensão. São Paulo: Parábola Editorial, 2008.

KOCH, Ingedore Villaça; ELIAS, Vanda Maria. Ler e compreender: os sentidos do texto. $2^{\mathrm{a}}$ ed. São Paulo: Contexto, 2006.

KÖCHE, Vanilda Salton; BOFF, Odete Maria Bonetti; PAVAN, Cinara Ferreira. Prática textual: atividades de leitura e escrita. $4^{\mathrm{a}}$ ed. Rio de Janeiro: Vozes, 2008.

ROJO, R. Escol@ conectada: os multiletramentos e as TICs. 1.ed. São Paulo: Parábola, 2013, p. 20.

SPADARO, Antonio. Web 2.0: redes sociais. São Paulo: Paulinas, 2013. 